\title{
BMJ Open Social support and depression among community dwelling older adults in Asia: a systematic review
}

\author{
Tengku Amatullah Madeehah Tengku Mohd, ${ }^{01,2,3}$ Raudah Mohd Yunus,, ${ }^{3,4}$ \\ Farizah Hairi, ${ }^{2,3}$ Noran N Hairi, ${ }^{2,3}$ Wan Yuen Choo ${ }^{2,3}$
}

To cite: Tengku Mohd TAM, Yunus RM, Hairi F, et al. Social support and depression among community dwelling older adults in Asia: a systematic review. BMJ Open 2019;9:e026667. doi:10.1136/ bmjopen-2018-026667

- Prepublication history and additional material for this paper are available online. To view these files, please visit the journal online (http://dx.doi. org/10.1136/bmjopen-2018026667).

Received 13 September 2018 Revised 29 April 2019

Accepted 30 May 2019

Check for updates

(C) Author(s) (or their employer(s)) 2019. Re-use permitted under CC BY-NC. No commercial re-use. See rights and permissions. Published by BMJ.

For numbered affiliations see end of article.

Correspondence to Dr Tengku Amatullah Madeehah Tengku Mohd; madeehah@usim.edu.my and Dr Farizah Hairi;

farizah@ummc.edu.my

\section{ABSTRACT}

Objectives This review aims to: (1) explore the social support measures in studies examining the association between social support and depression among community-dwelling older adults in Asia and (2) the evidence of association.

Design A systematic review was conducted using electronic databases of CINAHL, PubMed, PsychINF0, Psychology and Behavioural Sciences Collection, SocINDEX and Web of Science for articles published until the 11th of January 2018.

Eligibility criteria All observational studies investigating the association between social support and depression among community-dwelling older adults in Asia were included. Participants Older adults aged 60 years and more who are living in the community.

Exposure measures Social support.

Outcome measures Depression.

Results We retrieved 16356 records and screened 66 full-text articles. Twenty-four observational studies were included in the review. They consisted of five cohort studies and 19 crosssectional studies. Social support was found to be measured by multiple components, most commonly through a combination of structural and functional constructs. Perceived social support is more commonly measured compared with received social support. Good overall social support, having a spouse or partner, living with family, having a large social network, having more contact with family and friends, having emotional and instrumental support, good support from family and satisfaction with social support are associated with less depressive symptoms among community-dwelling older adults in Asia. Conclusions There were 20 different social support measures and we applied a framework to allow for better comparability. Our findings emphasised the association between good social support and decrease depression among older adults. Compared with western populations, family support has a greater influence on depression among community-dwelling older adults in Asia. This indicates that the family institution needs to be incorporated into designed programmes and interventions when addressing depression in the Asian context. Trial registration number CRD42017074897.

\section{INTRODUCTION}

The prevalence of depression among older adults in Asia ranges between $7.8 \%$ and $34.8 \% .^{1-6}$ As the older population continues to rise, the number of older adults with depression is expected to increase. Depression causes disability, ${ }^{7}$ decline in quality

\section{Strengths and limitations of this study}

- This systematic search was conducted in six databases using broad terminologies to capture as many relevant studies as possible.

- This review analysed social support measurements and categorised them according to relevant components, to enable comparison.

- The limitation of this review is that only studies published in English were included.

of life ${ }^{8}$ and higher risk of mortality. ${ }^{9}$ Poor health, disability and low social support are associated with depression among older adults, ${ }^{1011}$ whereas high social support results in reduced mortality, ${ }^{12}$ improved health ${ }^{13} 14$ and greater quality of life. ${ }^{15}$ Therefore, social support is a potential resource available to all individuals that could be enhanced and bring overall benefit to the older adults.

Social support is defined as an exchange of resources between at least two individuals in which either one perceives it as intended to enhance the well-being of the recipient. ${ }^{16}$ It has been described in two different constructs: structural versus functional ${ }^{17}$ and perceived versus received. ${ }^{18}$ Structural social support refers to an individual's organisational ties to other people and is measured in various forms such as size of social network, network composition, frequency of contact with network members and multiplexity of the relationships between the individual and network members. ${ }^{19}$ On the other hand, functional social support is the exchange of emotional, instrumental or tangible, informational and appraisal support. ${ }^{20} 21$ It is the qualitative aspect of social support which includes satisfaction of social support, having confidants and social isolation. ${ }^{1022}$ Social support can also be described in terms of received and perceived social support. Perceived social support refers to a person's potential access to social support, while received social 
support is the reported exchange or utilisation of social support resources by an individual. ${ }^{2324}$

Four systematic reviews have been conducted on this topic. ${ }^{1025-27}$ Two of them were conducted among general adults in the Middle East and Iran reviewing the association between social support and health outcomes, and mental health. ${ }^{26}{ }^{27}$ Gariépy and colleagues conducted a study examining social support and protection of depression among western countries among all ages from children to older adults. ${ }^{25}$ Only one systematic review analysed the concept of social relationships and depression specifically among older adults in 13 countries, including Asia. ${ }^{10}$ All of the systematic reviews reported consistent association between social support and mental health or depression. A summary table of the systematic reviews is included in online supplementary A. Cultural differences were reported with regard to the effects of frequency of contacts and marital status when comparing western to eastern countries. ${ }^{10}$ Therefore, we felt it necessary to gather all studies conducted in Asia focusing on social support, to explore further possible differences that may exist due to the diversity of norms, beliefs and lifestyles. For instance, the Asian population is known to be collectivist while the western society is said to embrace more individualism. ${ }^{28}$ Therefore, more emphasis is usually given to informal caregiving for old parents in Asian communities than dependency on state services and formal institutions. ${ }^{29}$ This also reflects how older adults' perception of social support and acceptance to it may vary across regions. This review fills in an important gap; it provides a greater understanding of the characteristics of social support and the relationship between social support and depression that is specific to the context of Asian elders.

Our study aims to gather, appraise and summarise all existing evidence pertaining to the relationship between social support and depression among community dwelling older adults in Asia. It seeks to answer the following questions: (1) How is social support measured in these studies? (2) What is the evidence on the relationship between social support and depression among community dwelling older adults in Asia?

\section{METHODS}

\section{Protocol and registration}

This systematic review was conducted according to the Preferred Reporting Systems for Systematic Reviews and Meta-Analyses (PRISMA) guidelines ${ }^{30}$ and has been registered with PROSPERO (registration number CRD42017074897). Studies included were: (1) English papers; (2) studies published until 11 January 2018. The inclusion criteria were: (1) the participants aged 60 years and more; (2) community-dwelling older adults and not living in institutions; (3) studies which mention social support as the exposure variable; (3) the outcome of interest is self-reported or diagnosed depression; (4) observational studies which included cross-sectional or case-control or cohort study designs; (5) associations were quantitatively analysed, using multivariable analysis with adjustment for confounders; (6) conducted in Asia, defined as the countries listed under the WHO South East Asia and WHO West-Pacific regional office, ${ }^{31}$ with the exclusion of countries in the Australasia region. Articles excluded were: (1) those with study subjects suffering from specific chronic diseases or living alone; (2) qualitative studies and (3) review papers and papers not considered as original studies.

\section{Information sources and search strategy}

Search was conducted in January 2018 using six electronic databases: CINAHL, PubMed, PsychINFO, Psychology and Behavioural Sciences Collection, SocINDEX and Web of Science. Four constructs were used to identify relevant keywords or search terms with the assistance of a librarian. They were 'social support', 'older adults', 'community dwelling' and 'health', respectively. Keywords such as 'social support', 'social relations', 'tangible support', 'older persons', 'aged', 'old', 'community-community dwelling', 'mental health' and 'depression' were included. Keywords were chosen based on previous relevant systematic reviews on social support and social relationships. An example of the search strategy is attached in online supplementary B. Each concept was searched individually using MeSH terms and title except for Web of Science, in which we used topic only. Within each concept, the Boolean operator 'OR' was used and all concepts were later combined using 'AND', to retrieve a total number of 16356 articles.

Hand searching was performed by snowballing all the references in the included studies. We also conducted a search on Google Scholar using the search terms 'social support' AND 'depression' AND 'community dwelling elderly', sorted according to relevance. We retrieved 7330 articles from Google scholar and the first 300 articles were screened. ${ }^{32}$ From this, five studies were included in the review. The remaining articles were not relevant for this systematic review.

The first step-title screening, was performed by one reviewer (TAMTM) to remove irrelevant topics. Two reviewers (TAMTM and RY) then independently screened the remaining titles with their abstracts, to select studies for the next phase. Discrepancies were resolved by consulting a third (WYC or FH) reviewer.

\section{Data extraction and quality appraisal}

Data from the studies were extracted using a predetermined data extraction form as attached in online supplementary C. Information extracted included title, year of publication, author, study design, sampling method, population, setting, sample size, exposure, outcome, tools of measurement, covariates and statistical outcomes from each paper. Data extraction was performed by one reviewer and cross-checked by two others. Any disagreements were discussed. Due to the heterogeneity of the studies, synthesis of the findings were narrative in nature. 


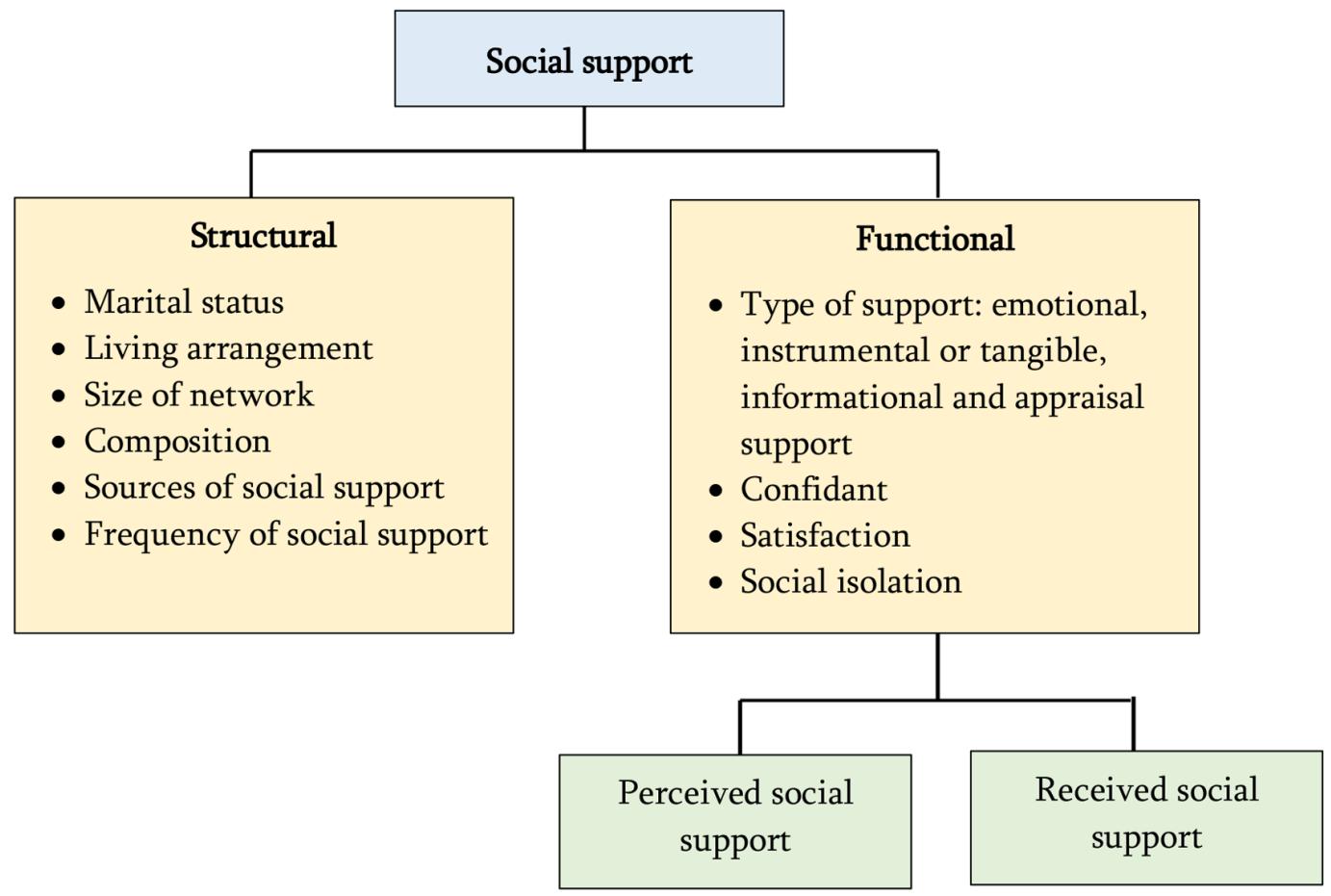

Figure 1 Conceptual framework of social support adapted from Cobbs (1976), ${ }^{81}$ Berkman et al $^{78}$ and Schwarzbach et al. ${ }^{10}$

Quality assessment was done using the Newcastle Ottawa Scale (NOS) for cross-sectional and cohort studies ${ }^{33} 34$ by one reviewer and double-checked by two other reviewers. Studies were categorised by the number of stars given. For cross-sectional studies, categorisation is as follows: low (1-3 stars), moderate (4-6 stars) and good (7-10). For cohort studies, categorisation is as follows: low (1-3 stars), moderate (4-6 stars) and good (7-9). The quality assessment tools are available as online supplementary D and $\mathrm{E}$. The adapted version of the cross-sectional NOS has been used in a previous systematic review. ${ }^{35}$

Due to the heterogeneity of the social support measurements, we operationalised social support as a broad term encompassing structural, functional, perceived and received social support. We combined all four concepts into one framework described in figure 1. We considered perceived and received social support part of functional support as it reflects how a person views the exchange of functions. ${ }^{10}$

\section{Patient and public involvement}

This study only reviewed previous published studies and did not involve any patients or public involvement.

\section{RESULTS}

The initial search resulted in 16361 articles. We removed 3929 duplicates. The remaining 12432 articles were screened by titles and abstract, and 12200 papers were excluded as they were irrelevant to our scope and objectives. A total of 68 articles were selected for full text screening, but two of them could not be retrieved. From the remaining 66 studies, 42 studies were excluded for several reasons: not meeting the inclusion criteria for the study population $(n=7)$; social support not being an exposure variable $(n=20)$; depression not being measured as an outcome $(n=7)$; did not adjust for potential confounders $(n=4)$ and being irrelevant from the systematic review topic $(n=4)$ (see online supplementary F). The PRISMA flowchart of study selection is illustrated in figure 2. Table 1 shows the final studies included in the analysis $(\mathrm{n}=24)$.

The studies were conducted in eight countries: China $(n=4)$, Japan $(n=4)$, Singapore $(n=4)$, Taiwan $(n=3)$, Hong Kong $(n=2)$, Korea $(n=2)$, Macau $(n=2)$, Thailand $(n=2)$ and one study conducted in both Japan and Korea. The prevalence of depression was reported in 12 studies and ranged from $7.8 \%$ to $46 \%$ (see online supplementary $\mathrm{G})$. Among the 24 studies, 5 were cohort studies while the remaining 19 adopted cross-sectional designs.

This review has a total number of 54682 participants with sample size ranging from 162 to 24 632. Most of the studies were of good quality $(n=17)$, with an average score of 7 (see online supplementary $\mathrm{H}$ ). Most of the sampling method used $(n=19)$ were universal sampling and random sampling and used local registry as the sampling frame. However, the quality was affected for the following reasons: no justification for sample size $(n=21)$, no description of non-responders $(n=23)$ and outcome measure based on self-report $(n=24)$.

\section{Social support definition and measurements}

Among the 24 studies, only two studies provided a clear definition of social support. ${ }^{36} 37$ Both described social support as resources accessible to a person or that they 


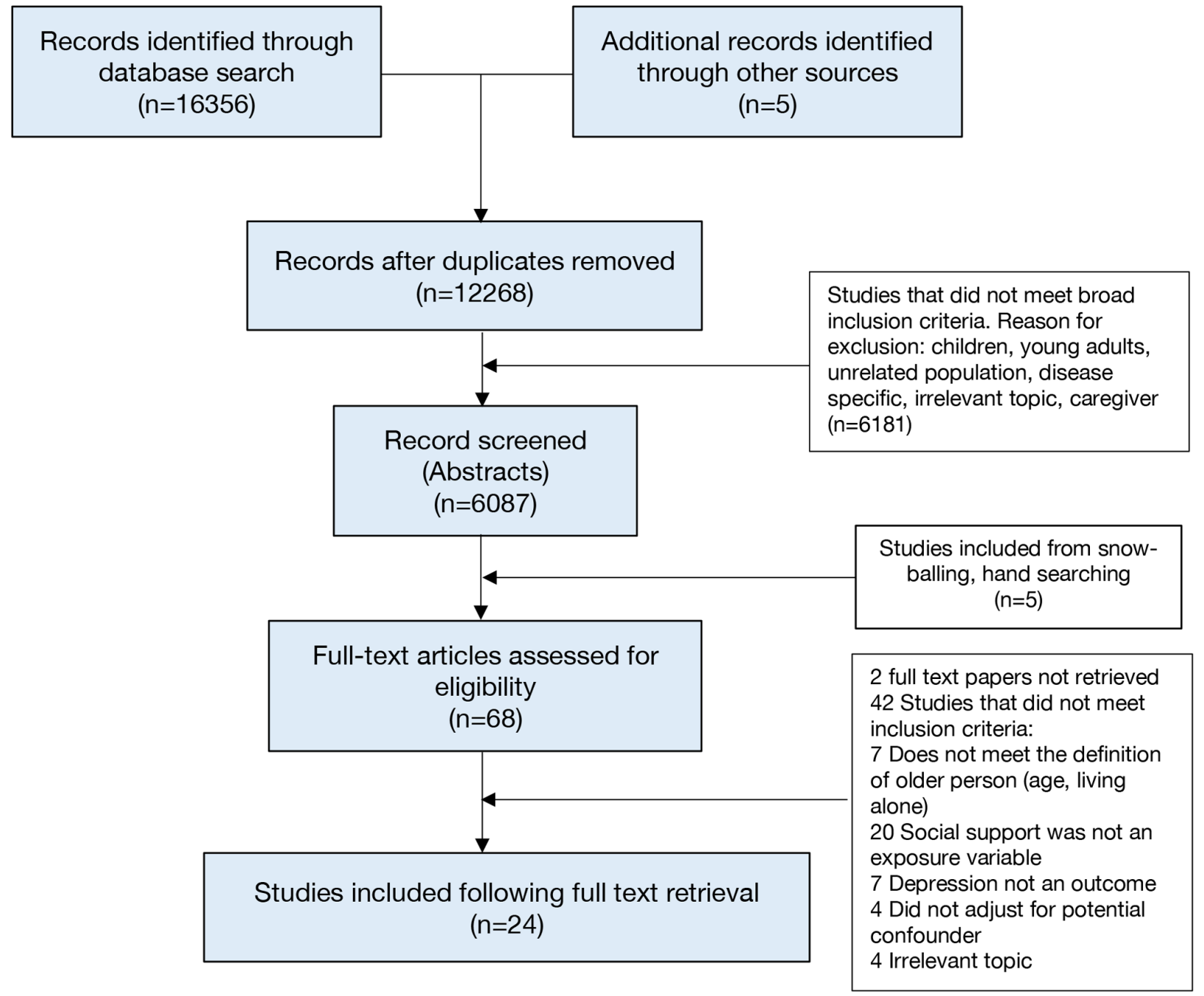

Figure 2 PRISMA flowchart of the review. PRISMA, Preferred Reporting Systems for Systematic Reviews and Meta-Analyses.

perceive are available. Other studies described measurements of social support. The majority of studies had two or more measures of social support $(\mathrm{n}=18)$, consisting of both structural and functional measures ( $\mathrm{n}=14)$ (table 2). Five studies assessed social support using one measurement. ${ }^{36-41}$ The usage of a multicomponent measure is more comprehensive in measuring social support, but it leads to heterogeneity in the results. For example, some studies do not just report the types of social support measure, but subcategorised it into the source of the social support (eg, emotional support given by family). Results are therefore not comparable.

Social support was measured by 10 different components. Table 2 lists all the social support measurements from included studies. The five most common measures were type of support $(n=14)$, frequency of contact $(n=12)$, living arrangement $(n=11)$, size of social network $(n=8)$ and sources of social support $(n=8)$. Structural support measures found in the studies are marital status, living arrangement, size of network, network composition, sources of social support, frequency of social contact and children nearby. Functional support was measured by types of social support, the presence of confidant and satisfaction of support. A detailed description of social support measurements in each study is attached in online supplementary I.

The results of the association for each social support component with depression are summarised in table 3 and described in detailed in online supplementary J. First, we described the results within the structural social support. Older adults who were married or have a partner, have fewer depressive symptoms. ${ }^{42-45}$ Second, living arrangement was found to be significantly associated with depressive symptoms in three studies. ${ }^{40} 4647 \mathrm{We}$ found that living with family was associated with lower rates of depression. ${ }^{48}$ Third, in terms of social network size, three studies showed significant association between having a larger size of network and fewer depressive symptoms. ${ }^{42} 4849$ Apart from size, the composition of social network was also shown to be associated with depression. Two studies showed that a larger social network composed of mostly family members is associated with reduced rate of depression compared with having friends. ${ }^{49}{ }^{50}$ One study showed specifically having a social network composed of $25 \%-50 \%$ of family members was associated with fewer depressive symptoms (Estimate 


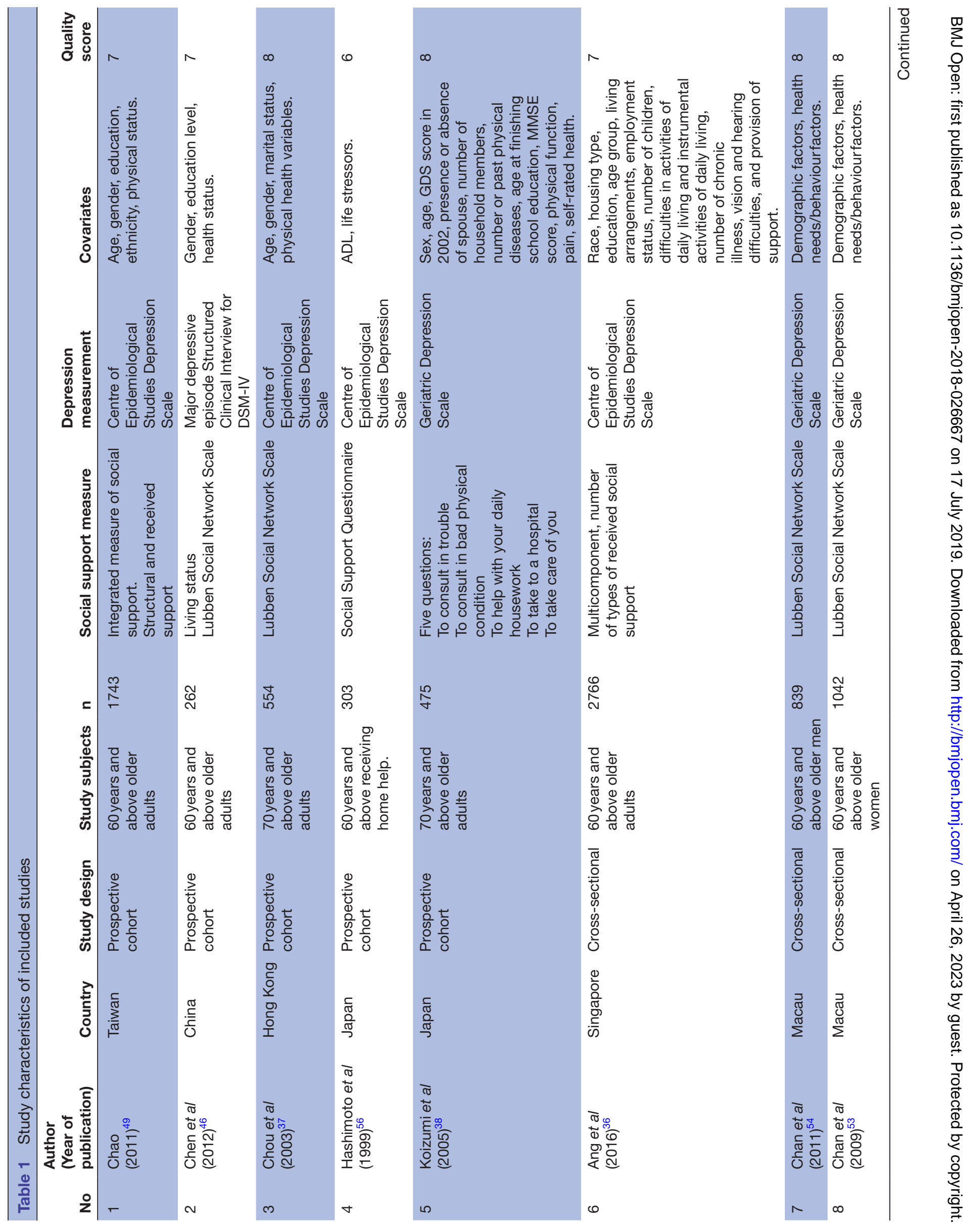




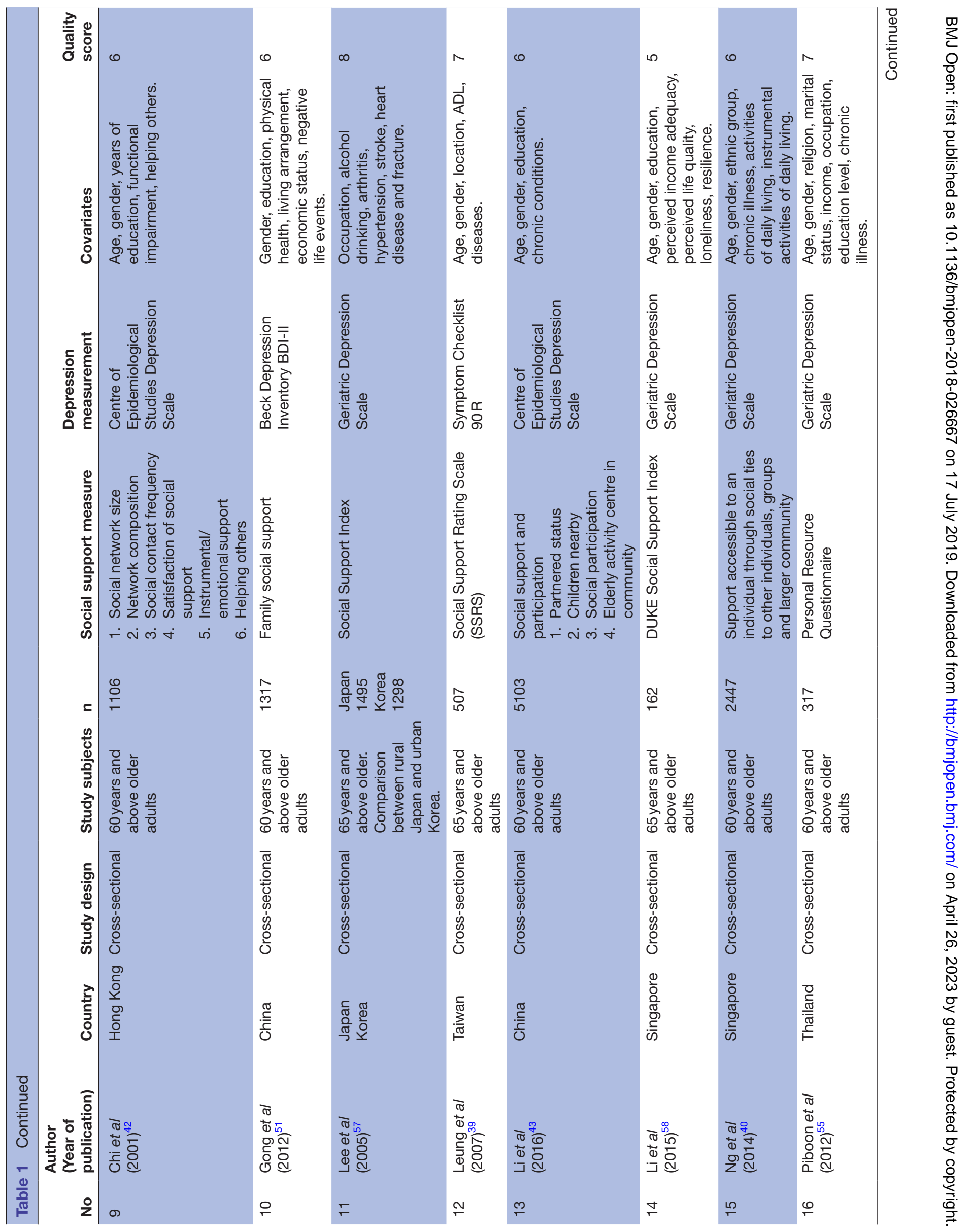




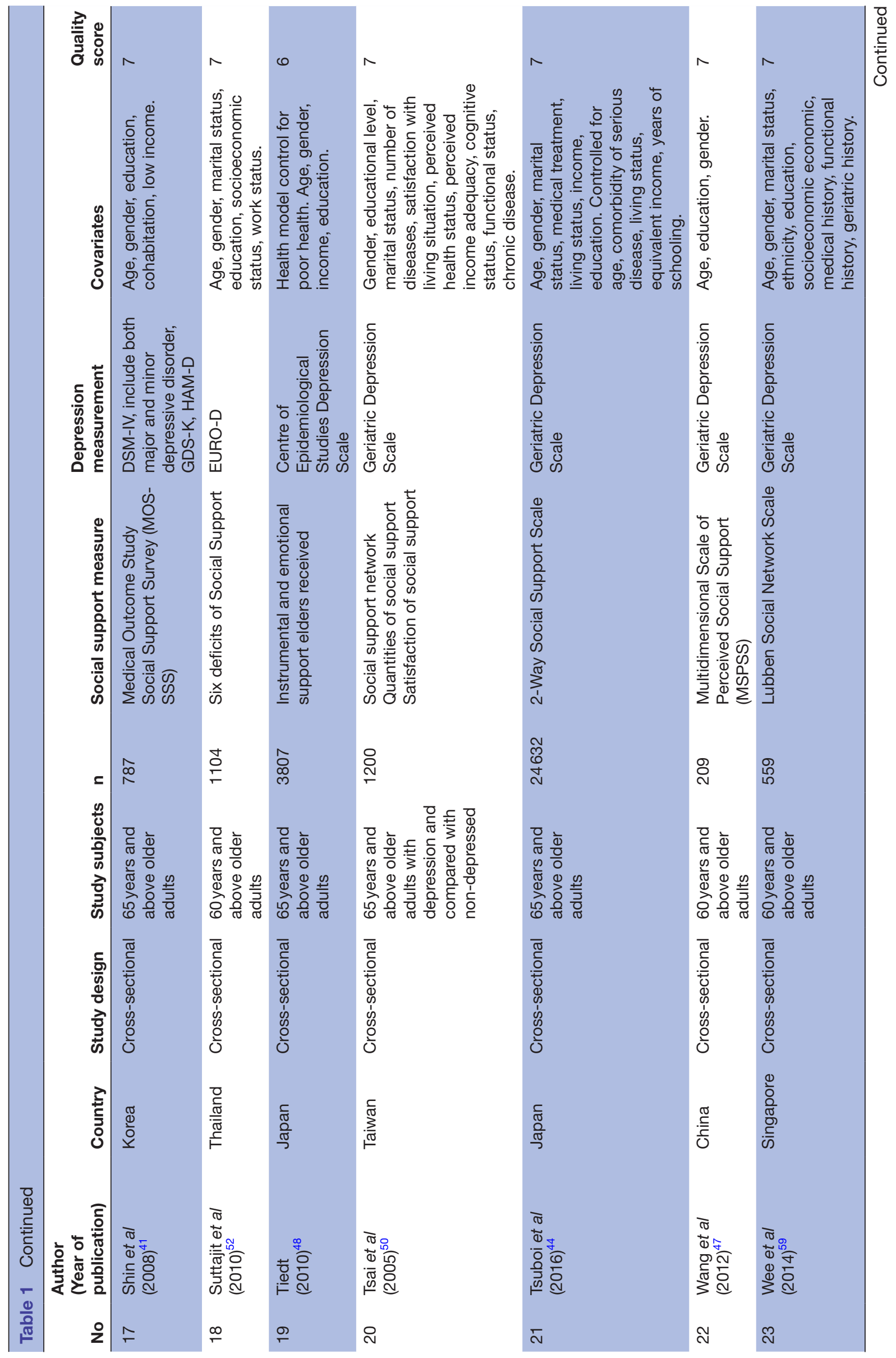



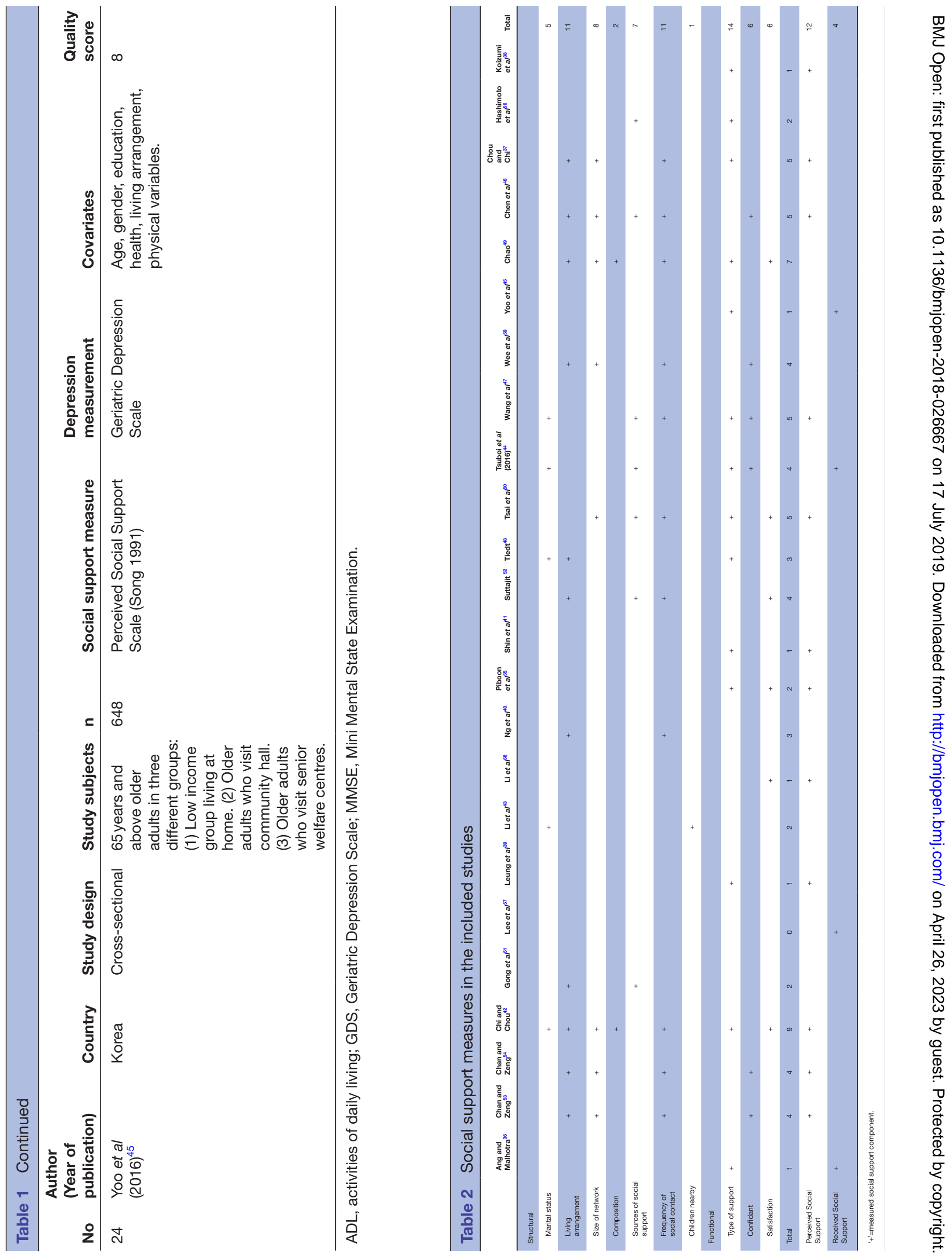


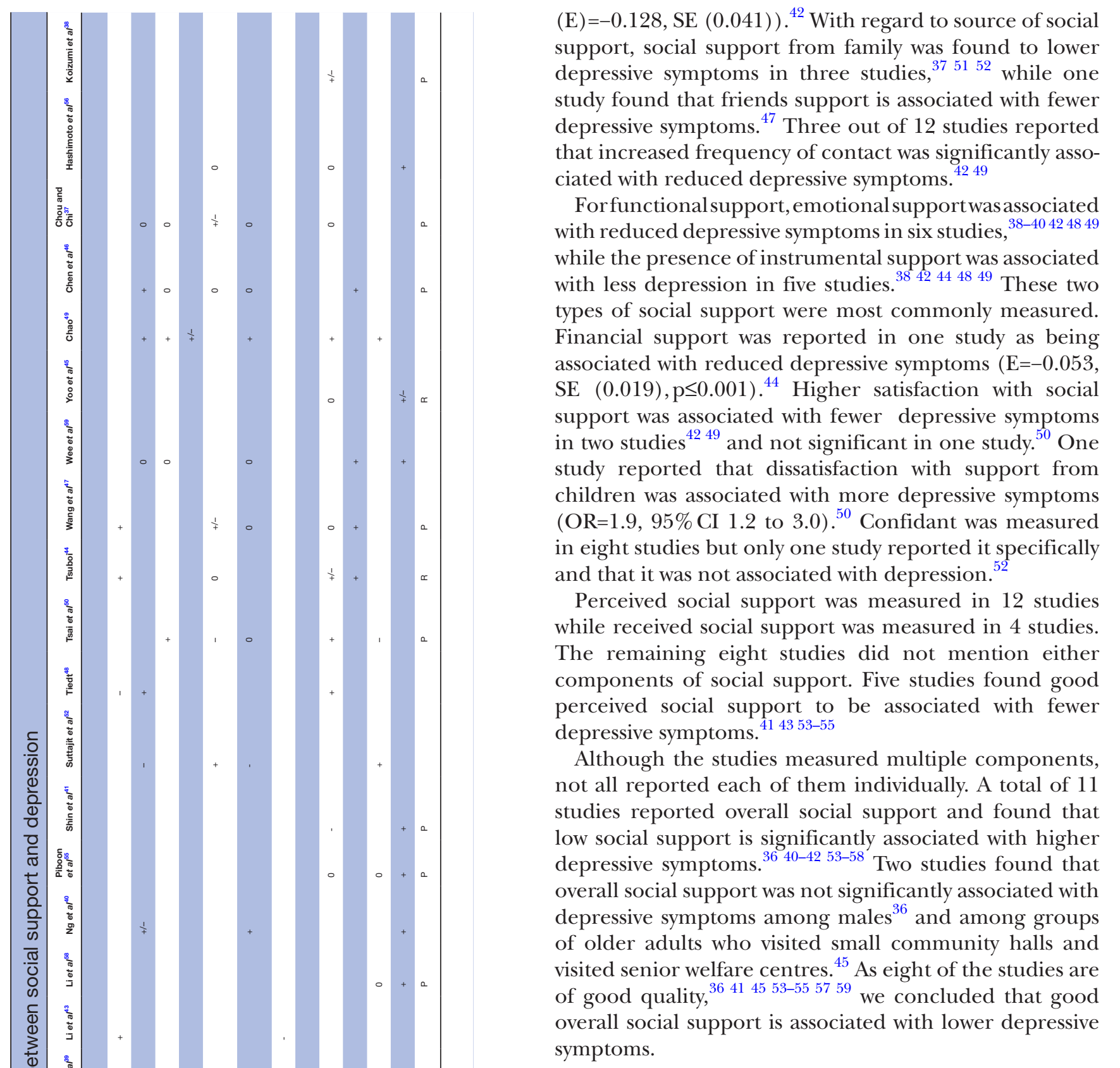

\section{DISCUSSION}

We found that social support is a multidimensional concept and there is no standardised method in measuring or reporting them. In total, 20 different social support measurements were used. This makes comparison between studies difficult unless a framework is used to group the results. From the measurements of social support, we propose a framework that includes perceived and received social support under functional social support as depicted in figure 1. Perceived and received social support has been recognised previously to be a function of social support. ${ }^{60}{ }^{61}$ Questions measuring received social support enquire regarding the frequency of receiving specific types of social support, ${ }^{28}$ for example, whether the respondents receive financial, house chores, food or emotional support. ${ }^{36} 48$ Perceived 
social support measures asks indirectly whether the individual has family or friends that can provide them with certain types of social support. ${ }^{58}$ Using this framework structure, we were able to categorise perceived and received social support as functional social support, making comparison easier.

This review found that good overall social support, having a spouse or partner, living with family, having a large social network, having more contact with family and friends, having emotional and instrumental support, good support from family and satisfaction with social support are associated with less depressive symptoms among the community-dwelling older adults in Asia. In terms of structural measures of social support, our results are similar to previous studies with regard to marital status, contact frequency and social network size. ${ }^{25} 62$ Compared with findings in western countries that emphasise the association between spousal and friends support with depression, Asian elders are more affected by family support. ${ }^{10}$ This highlights an important aspect of cultural difference. Given the tradition of filial piety in many Asian countries, older adults tend to rely on children and family members for care in old age, thus explaining the source of social support that affects their mental well-being more. Therefore, the approach of supporting elders in Asia should be more focused on assisting and educating families in caring for their elder members.

Filial piety is an important concept in the Asian culture with the core value of respecting one's parents. It was introduced in Confucianism centuries ago and revolves around the responsibility of a son or daughter to care for their parents. ${ }^{25}$ A similar practice is also present in Hinduism $^{63}$ and Islam, ${ }^{64}$ the two other religions which are dominant in Asia. Although the studies only included south-east and east Asian countries, studies from south Asia were not included as they did not fulfil the inclusion criteria. ${ }^{65-68}$ The results of the south Asian studies mirrored our findings with fewer depressive symptoms reported among Indian older adults with good social support. However, urbanisation and industrialisation are causing a shift in this trend. ${ }^{69}$ Since the number of multiple generational household is reducing, parents have less expectation on their children to look after them. ${ }^{69} 70$ This review has shown that children still have an impact on the older adults' depressive symptoms. Living with family, especially children, is significantly associated with less depressive symptoms but the evidence is inadequate due to the small number of studies. Good family support which included support from children was also associated with reduced depression. This is in stark contrast to studies conducted in the west, where spousal or friends support is more important. ${ }^{1071}$ More studies on the effect of filial piety on depression could be explored further. Given the trends of westernisation, a shift in social norms and youth rural-urban migration, the dynamics of filial piety in Asian countries may undergo change in the future.

\section{Strengths and limitations}

This systematic review is the first to be conducted in Asia among community-dwelling older adults. Community-dwelling older adults have potentially more access to social support compared with institutionalised older adults. Research to enhance the health outcome of this population is important to enable them to live in the community as long as possible. This review also highlighted that social support is a broad and heterogeneous concept. But, despite the heterogeneity, we analysed the measurements of social support by applying a social support framework which encompassed two important constructs. However, there are a few limitations. First, most of the studies included were cross-sectional in design. Only five studies were cohorts, and the reported social support components in these studies are limited. Therefore, a causal relationship between social support components and depression cannot be adequately confirmed. Second, a single reviewer conducted the first phase of the title screening. The possibility of bias or error at this stage cannot be ruled out. However, the final papers were discussed with the other reviewers. We excluded non-English publications and this might have caused systematic bias through omission of potentially relevant studies. Despite the limitations of this review, our strength lies in our systematic search in which multiple keywords and broad terminologies were used to capture as many articles as possible.

\section{Comparison with other studies}

Emotional and instrumental social support are the most commonly measured functional support and are found to be associated with lower depressive symptoms. This concurs with previous studies. ${ }^{10} 72$ But other types of functional support, namely appraisal and informational social support, have not been studied and should be explored in future. There were also other measures of social support found, such as difficulty in relationships ${ }^{73}$ poor positive social interaction ${ }^{52}$ providing social support ${ }^{414249}$ and social isolation. ${ }^{44}$ These measures were not included as they did not reflect the definition of functional support used in this review.

Perceived social support is more commonly associated with depression compared to received support. High perceived social support has been found to be associated with reduced depressive symptoms. This corroborates previous findings that perceived social support has a higher impact on mental health than received social support. ${ }^{74-76}$ Perceived social support buffers the effect of stress by reassuring the person that help is available and thus enhance the individual's coping abilities in dealing with stressful events. ${ }^{77}$ On the contrary, received social support is thought to cause dependency and a sense of helplessness by undermining a person's self-esteem. ${ }^{78}$

\section{Implications on research and policies}

This review has emphasised the issue of heterogeneity of social support measurements in the literature and the impact of specific types of social support on depression among 
community-dwelling older adults. In the future, applying a social support framework should be the way forward for easier comparison of findings. In the Asian context, research on the changing trends of filial piety and its impact on older adults should be explored further. Although there have been studies conducted in China, Singapore and Hong Kong, ${ }^{70}{ }^{80}$ it is still unknown in other parts of Asia. In addition, functional social support is the most commonly measured support, especially emotional and instrumental support. Future research should thus consider measuring informational and appraisal support or explore other measures of functional social support. Our findings can be incorporated into the geriatric screening programme in the primary healthcare setting in Asia. Questions regarding social support should be included and used to assist in early detection of those at risk of depression. Findings of this review also point to the role that family members-especially adult children—can play in remedying depression of old parents. This understanding can be leveraged by interventions such as group therapies or family mediation.

\section{CONCLUSION}

Social support measurements consist of multiple components and they vary between studies. However, by applying a social support framework to classify these measurements, a clearer association between social support and depression can be seen. This systematic review has also highlighted the important role of family as a source of support in reducing depressive symptoms among community-dwelling older adults in Asia. We recommend further exploration and investigation of social support and its components among older adults, and for them to be used to predict and improve health outcomes in the primary healthcare setting.

\section{Author affiliations}

${ }^{1}$ Faculty of Medicine and Health Sciences, Universiti Sains Islam Malaysia Kampus Pandan Indah, Kuala Lumpur, Malaysia

${ }^{2}$ Department of Social and Preventive Medicine, Faculty of Medicine, University of Malaya, Kuala Lumpur, Malaysia

${ }^{3}$ Centre for Epidemiology and Evidence-Based Practice, Department of Social and Preventive Medicine, Faculty of Medicine, University of Malaya, Kuala Lumpur, Malaysia

${ }^{4}$ Department of Public Health Medicine, Faculty of Medicine, Universiti Teknologi MARA, Sungai Buloh, Malaysia

Acknowledgements We would like to thank Ranita Hisham Shumugam, the librarian, and fellow colleagues Awatef Amer Nordin and Sakinah Ahmad for their assistance in this systematic review.

Contributors TAMTM conducted the search, screening of papers, data extraction and wrote the review. NNH, YWC, FH, RMY contributed towards the design, reviewing the papers, revising and final approval of the manuscript.

Funding This work was supported by the University of Malaya Grand Challenge Grant on Preventing Elder Abuse and Neglect Initiative (GC001B-14 HTM and GC001D-14HTM).

Competing interests TAMTM reports financial and non-financial support from the University of Malaya, Islamic Science University of Malaysia and the Ministry of Higher Education Malaysia, outside the submitted work. RMY reports financial and non-financial support from the University of Malaya, Universiti Teknologi MARA and the Ministry of Higher Education Malaysia, outside the submitted work. FH, NNH and WYC report grants and non-financial support from University of Malaya and the Ministry of Higher Education Malaysia, outside the submitted work.
Patient consent for publication Not required.

Provenance and peer review Not commissioned; externally peer reviewed.

Data sharing statement All data relevant to the study are included in the article or uploaded as supplementary information.

Open access This is an open access article distributed in accordance with the Creative Commons Attribution Non Commercial (CC BY-NC 4.0) license, which permits others to distribute, remix, adapt, build upon this work non-commercially, and license their derivative works on different terms, provided the original work is properly cited, appropriate credit is given, any changes made indicated, and the use is non-commercial. See: http://creativecommons.org/licenses/by-nc/4.0/.

\section{REFERENCES}

1. Thongtang $\mathrm{O}$, Sukhatunga $\mathrm{K}, \mathrm{Ngam}$ thipwatthana $\mathrm{T}$, et al. Prevalence and incidence of depression in the Thai elderly. J Med Assoc Thai 2002;85:540-4.

2. Niti M, Ng TP, Kua EH, et al. Depression and chronic medical illnesses in Asian older adults: the role of subjective health and functional status. Int J Geriatr Psychiatry 2007;22:1087-94.

3. Gao S, Jin Y, Unverzagt FW, et al. Correlates of depressive symptoms in rural elderly Chinese. Int J Geriatr Psychiatry 2009;24:1358-66.

4. Malhotra R, Chan A, Malhotra C, et al. Prevalence, awareness, treatment and control of hypertension in the elderly population of Singapore. Hypertens Res 2010;33:1223-31.

5. Ma X, Xiang YT, Li SR, et al. Prevalence and sociodemographic correlates of depression in an elderly population living with family members in Beijing, China. Psychol Med 2008;38:1723-30.

6. Lu CH, Liu CY, Yu S. Depressive disorders among the Chinese elderly in a suburban community. Public Health Nurs 1998;15:196-200.

7. Greenglass E, Fiksenbaum L, Eaton J. The relationship between coping, social support, functional disability and depression in the elderly. Anxiety Stress Coping 2006;19:15-31.

8. Gurland B. The impact of depression on quality of life of the elderly. Clin Geriatr Med 1992;8:377-86.

9. Blazer DG, Hybels CF, Pieper CF. The association of depression and mortality in elderly persons: a case for multiple, independent pathways. J Gerontol A Biol Sci Med Sci 2001;56:M505-9.

10. Schwarzbach M, Luppa M, Forstmeier S, et al. Social relations and depression in late life-a systematic review. Int J Geriatr Psychiatry 2014;29:1-21.

11. Blazer DG. Depression and social support in late life: A clear but not obvious relationship. Aging Ment Health 2005;9:497-9.

12. Blazer DG. Social support and mortality in an elderly community population. Am J Epidemiol 1982;115:684-94.

13. Reblin M, Uchino BN. Social and Emotional Support and It's Implication for Health [Electronic Version]. Curr Opin Psychiatry 2008;21:201-5.

14. Hakulinen C, Pulkki-Råback L, Jokela M, et al. Structural and functional aspects of social support as predictors of mental and physical health trajectories: Whitehall II cohort study. J Epidemiol Community Health 2016;70:710-5.

15. Layte R, Sexton E, Savva G. Quality of life in older age: evidence from an Irish cohort study. J Am Geriatr Soc 2013;61(Suppl 2):S299-305.

16. Oxman TE, Berkman LF, Kasl S, et al. Social support and depressive symptoms in the elderly. Am J Epidemiol 1992;135:356-68.

17. Shumaker SA, Brownell A. Toward a Theory of Social Support: Closing Conceptual Gaps. J Soc Issues 1984;40:11-36.

18. Cobb S. Social support as a moderator of life stress. Psychosom Med 1976;38:300-14.

19. Haber MG, Cohen JL, Lucas T, et al. The relationship between selfreported received and perceived social support: A meta-analytic review. Am J Community Psychol 2007;39:133-44.

20. Thoits PA. Conceptual, methodological, and theoretical problems in studying social support as a buffer against life stress. J Health Soc Behav 1982;23:145-59.

21. House JS. Work Stress and Social Support: Addison-Wesley, 1981.

22. Tajvar M. Family, social support and health status of older people in Tehran, 2015.

23. Uchino BN. Understanding the Links Between Social Support and Physical Health. A Life-Span Persepctive with Emphasis on the Separability of Perceived and Received Support. Psychol Sci 2009;4:236-55.

24. Haber MG, Cohen JL, Lucas T, et al. The relationship between selfreported received and perceived social support: a meta-analytic review. Am J Community Psychol 2007;39:133-44. 
25. Gariépy G, Honkaniemi H, Quesnel-Vallée A, et al. Social support and protection from depression: systematic review of current findings in Western countries. Br J Psychiatry 2016;209:284-93.

26. Harandi TF, Taghinasab MM, Nayeri TD. The correlation of social support with mental health: A meta-analysis. Electron Physician 2017;9:5212-22.

27. Tajvar M, Fletcher A, Grundy E, et al. Social support and health of older people in Middle Eastern countries: a systematic review. Australas J Ageing 2013;32:71-8.

28. North MS, Fiske ST, North MS. Modern Attitudes Toward Older Adults in the Aging World: A Cross-Cultural Meta-Analysis. Psychol Bull 2015;141:993-1021.

29. Nations U. Living Arrangements of Older Persons: A Report on an Expanded International Dataset. New York, 2017.

30. Moher D, Liberati A, Tetzlaff J, et al. Preferred reporting items for systematic reviews and meta-analyses: the PRISMA statement. Ann Intern Med 2009;151:264-9.

31. WHO. WHO regional office. 2018. http://www.who.int/about/regions/ en/ [Accessed 1 Jan 2018].

32. Haddaway NR, Collins AM, Coughlin D, et al. The role of Google Scholar in evidence reviews and its applicability to grey literature searching. PLoS One 2015;10:e0138237.

33. Wells G, Shea B, O'Connell D, et al. Newcastle-Ottawa quality assessment scale cohort studies, 2014.

34. Wells G, Shea B, O'Connell D, et al. Evaluation of the NewcastleOttawa Scale (NOS): an assessment tool for evaluating the quality of non-randomized studies in meta analyses. 2014. http://www.ohri.ca/ programs/clinical_epidemiology/oxford.asp [Accessed 15 Dec 2017].

35. Yunus RM, Hairi NN, Choo WY. Consequences of Elder Abuse and Neglect: A Systematic Review of Observational Studies. Trauma Violence Abuse 2019;20:197-213.

36. Ang S, Malhotra R. Association of received social support with depressive symptoms among older males and females in Singapore: Is personal mastery an inconsistent mediator? Soc Sci Med 2016;153:165-73.

37. Chou KL, Chi I. Reciprocal relationship between social support and depressive symptoms among Chinese elderly. Aging Ment Health 2003;7:224-31.

38. Koizumi Y, Awata S, Kuriyama S, et al. Association between social support and depression status in the elderly: results of a 1-year community-based prospective cohort study in Japan. Psychiatry Clin Neurosci 2005;59:563-9.

39. Leung KK, Chen CY, Lue BH, et al. Social support and family functioning on psychological symptoms in elderly Chinese. Arch Gerontol Geriatr 2007;44:203-13.

40. Ng CW, Tan WS, Gunapal PP, et al. Association of Socioeconomic Status (SES) and Social Support with Depressive Symptoms among the Elderly in Singapore. Ann Acad Med Singapore 2014;43:576-87.

41. Shin JK, Kim KW, Park JH, et al. Impacts of poor social support on general health status in community-dwelling korean elderly: the results from the Korean longitudinal study on health and aging. Psychiatry Investig 2008;5:155-62.

42. Chi I, Chou KL. Social support and depression among elderly Chinese people in Hong Kong. Int J Aging Hum Dev 2001;52:231-52.

43. Lw L, Liu J, Xu H, et al. Understanding Rural-Urban Differences in Depressive Symptoms Among Older Adults in China. J Aging Heal 2016;28:341-62.

44. Tsuboi H, Hirai H, Kondo K. Giving social support to outside family may be a desirable buffer against depressive symptoms in community-dwelling older adults: Japan gerontological evaluation study. Biopsychosoc Med 2016;10:1-11.

45. Yoo JS, Chang SJ, Kim HS. Prevalence and Predictive Factors of Depression in Community-Dwelling Older Adults in South Korea. Res Theory Nurs Pract 2016;30:200-11.

46. Chen $\mathrm{S}$, Conwell $\mathrm{Y}$, Vanorden $\mathrm{K}$, et al. Prevalence and natural course of late-life depression in China primary care: a population based study from an urban community. J Affect Disord 2012;141:86-93.

47. Wang J, Zhao X. Family functioning and social support for older patients with depression in an urban area of Shanghai, China. Arch Gerontol Geriatr 2012;55:574-9.

48. Tiedt AD. The gender gap in depressive symptoms among Japanese elders: evaluating social support and health as mediating factors. $J$ Cross Cult Gerontol 2010;25:239-56.

49. Chao SF. Assessing social support and depressive symptoms in older Chinese adults: a longitudinal perspective. Aging Ment Health 2011;15:765-74.

50. Tsai YF, Yeh SH, Tsai HH. Prevalence and risk factors for depressive symptoms among community-dwelling elders in Taiwan. Int J Geriatr Psychiatry 2005;20:1097-102.

51. Gong Y, Wen X, Guan C, et al. The associations between family characteristics and depressive symptoms in older adults: a community-based survey in rural China. Int Psychogeriatr 2012;24:1226-34.

52. Suttajit S, Punpuing S, Jirapramukpitak T, et al. Impairment, disability, social support and depression among older parents in rural Thailand. Psychol Med 2010;40:1711-21.

53. Chan MF, Zeng W. Investigating factors associated with depression of older women in Macau. J Clin Nurs 2009;18:2969-77.

54. Chan MF, Zeng W. Exploring risk factors for depression among older men residing in Macau. J Clin Nurs 2011;20:2645-54.

55. Piboon K, Subgranon R, Hengudomsub P, et al. A causal model of depression among older adults in Chon Buri Province, Thailand. Issues Ment Health Nurs 2012;33:118-26.

56. Hashimoto K, Kurita H, Haratani T, et al. Direct and buffering effects of social support on depressive symptoms of the elderly with home help. Psychiatry Clin Neurosci 1999;53:95-100.

57. Lee Y, Shinkai S. Correlates of cognitive impairment and depressive symptoms among older adults in Korea and Japan. Int $J$ Geriatr Psychiatry 2005;20:576-86.

58. Li J, Theng YL, Foo S. Depression and Psychosocial Risk Factors among Community-Dwelling Older Adults in Singapore. J Cross Cult Gerontol 2015;30:409-22.

59. Wee LE, Yong YZ, Chng MW, et al. Individual and area-level socioeconomic status and their association with depression amongst community-dwelling elderly in Singapore. Aging Ment Health 2014;18:628-41.

60. Lin N, Ye X, Ensel WM. Social support and depressed mood: a structural analysis. J Health Soc Behav 1999;40:344-59.

61. Holt-Lunstad J, Smith TB, Layton JB. Social relationships and mortality risk: a meta-analytic review. PLoS Med 2010;7:e1000316.

62. Lakey B, Orehek E. Relational regulation theory: a new approach to explain the link between perceived social support and mental health. Psychol Rev 2011;118:482-95.

63. Gupta B. Modernity and the Hindu joint family system: A problematic interaction. Int J World Peace 1994:11:37-60.

64. a OB, SM S, Othman N. Filial piety in Confucianism and Islam: A comparative literary analysis of Qur'an, Hadith, and four Chinses classics. Islam Civilisational Renew 2011;3:133.

65. Patil B, Pinto C, Shah H, et al. Study of perceived and received social support in elderly depressed patients. J Geriatr Ment Heal 2014;1:28.

66. Rajendra K R. A Sociological study on the Prevalence of Depression among Elderly. IOSR J Humanit Soc Sci 2014;19:24-6.

67. Barua A, Acharya D, Nagaraj K, et al. Depression in Elderly: A crosssectional study in rural South India Depression in Elderly. 2015.

68. Munshi Y, Iqbal M, Rafique ZA H. Geriatric Morbidity Pattern and Depression in Relation to Family Support in Aged Population of Kashmir Valley. Internet J Geriatr Gerontol 2007;4:1-5.

69. Chi I, Chappell NL, Lubben J. Elderly Chinese in Pacific Rim Countires: Social Support and Integration: Hong Kong University Press, 2011.

70. Mehta KK, Ko H. Filial piety revisited in the context of modernizing Asian societies. Geriatr Gerontol Int 2004;4:S77-8.

71. Cheng S, Chan ACM. Filial Piety and Psychological Well-Being in Well Older Chinese. , 2018:61, 262-9.

72. Poulin J, Deng R, Ingersoll TS, et al. Perceived family and friend support and the psychological well-being of American and Chinese elderly persons. J Cross Cult Gerontol 2012;27:305-17.

73. Santini ZI, Koyanagi A, Tyrovolas S, et al. The association between social relationships and depression: a systematic review. J Affect Disord 2015;175:53-65.

74. Fiori KL, Denckla CA. Social support and mental health in middleaged men and women: a multidimensional approach. J Aging Health 2012;24:407-38.

75. Taylor MG, Lynch SM. Trajectories of Impairment, Social Support. and Depressive Symptoms in Later Life. 2018;59:238-46.

76. Yang Y, Journal S, Behavior S, et al. How Does Functional Disability Affect Depressive Symptoms in Late Life? The Role of Perceived Social Support and Psychological Resources. : American Sociological Association How Does Functional Disability Affect Depressive Symptoms in Late Li, 2018:47: 355-72.

77. Kawachi I, Berkman LF. Social ties and mental health. $J$ Urban Health 2001;78:458-67.

78. Berkman LF, Glass T. Social integration, social networks, social support, and health. Soc Epidemiol 2000;1:137-73.

79. Cheng ST, Chan AC. Filial piety and psychological well-being in well older Chinese. J Gerontol B Psychol Sci Soc Sci 2006;61:P262-9.

80. Acy N, Phillips DR, Wkm L. Persistence and challenges to filial piety and informal support of older persons in a modern Chinese society: A case study in Tuen Mun, Hong Kong. J Aging Stud 2002;16:135-53.

81. Cobb S. Social Support as a Moderator of Life Stress. Psychosom Med 1976;38:300-14. 